\title{
Fatigue properties of strained very thin 304 stainless steel sheets
}

\author{
Ammar Adil Al-Bakri, ${ }^{1,2}$, Zainuddin Sajuri ${ }^{1^{*}}$, M. Abdulrazzaq ${ }^{3}$, Ahmad Kamal \\ Ariffin $^{1}$ and Mohd Salehudin Fafmin ${ }^{1}$ \\ ${ }^{1}$ Department of Mechanical and Materials Engineering, \\ Faculty of Engineering \& Built Environment, 43600 UKM Bangi, Selangor, Malaysia \\ *Email: ammaralbakry@siswa.ukm.edu.my; zsajuri@ukm.edu.my \\ ${ }^{2}$ Department of Machinery and Equipment Engineering Techniques, Technical College \\ Al-Musaib, Al-Furat Al-Awsat Technical University, Al-Musaib, Babil 51009, Iraq \\ ${ }^{3}$ Material Engineering Department, College of Engineering, \\ 58002 Al-Qadisiyyah University, Iraq
}

\begin{abstract}
This paper aims to study the properties of $300 \mu \mathrm{m}$ thickness 304 stainless steel. This research topic was selected considering the high demand for the production of small products such as smart phones, solar systems, hard drives, etc. Stainless steel was chosen for its low cost, suitable weight, and good mechanical properties in terms of strength and deformation compared to other materials. However, specimen size and strain may affect the results achieved. In this study, the effects of 2\% and 5\% strains on the fatigue strength of very thin 304 stainless steel sheets were investigated. Fatigue samples were cut into dumbbell-shapes with a rectangular cross-section as per ASTM E8. The tensile testing results showed that $300 \mu \mathrm{m}$ thickness heat-treated specimen sheets had less strain hardening with clear evidence of yielding. The fatigue test showed that higher strain values lengthened the fatigue life cycles of the stainless steel specimens. From this study, it can be concluded that tensile strain can improve the fatigue strength of very thin 304 stainless steel sheets.
\end{abstract}

Keywords: Thin sheet; tensile properties; hardness; fatigue strength; fracture behaviour.

\section{INTRODUCTION}

Owing to the fast-paced technological development, stainless steel is widely used in many industries. The properties of stainless steel make it suitable as a component in many industrial applications such as in chemical as reported by Marques et al. [1] and automotive industries as reported by Wright, Lei et al., Ha et al, Shah et al. and Jamil et al. [2-6], electronic devices as mentioned by Lee et al. [7], medical instruments as reported by Hadrboletz et al. and Connolley et al. [8,9], and other industries as mentioned by Bell, Nilsson and Molak et al. [10-12]. The popularity of stainless steel can be attributed to its ability to withstand high stress and operate at high temperatures. In recent years, the market demand for products such as pin connectors, micro-screws, springs, IC sockets, micro-gears and micro-shafts has increased significantly due to the downsizing of products as reported by Engel and Eckstein, Su et al., and Liu et al. [13-15]. The fact that material properties change with specimen sizes has been well-known for several years as mentioned by researchers Neugebauer, and Doerner et al. [16, 17]. 
Miniaturisation technology is now crucial in the fabrication of micro parts. When the size of a material is decreased to micro-scale, changes occur in its mechanical behaviour and such effects are called size effects as reported by Chan et al. [18]. Size effect is characterised by grain size, dimension of the specimen and size of the surface topography. Materials demonstrate mechanical properties such as modulus of elasticity, tensile strength, elongation, hardness and fatigue limit [19-22], and present their elastic and non-elastic behaviour when a certain force is applied. This indicates the suitability of a material to certain mechanical applications [23-25]. The tensile test is a method used to evaluate the structural response of steel to applied force with the result expressed as a relationship between stress and strain. The current study follows several previous researches that had dealt with macroscopic and microscopic behaviour and fatigue properties of pre-hardened austenitic stainless steel [26-29].Plastic deformation during forming can lead to deformation-induced transformation from the original ductile austenite phase to a stronger martensite [30-33]. In general, the formation of martensite depends on chemical composition, temperature, stress state, strain and strain rate [34-36]. The influence the strain rate has on mechanical properties of 304 stainless steels has also been reported by Refs.[37-42]. Over the last four decades, the thickness of car bodies has reduced significantly from $1.5 \mathrm{~mm}$ to less than $0.5 \mathrm{~mm}$. This is mainly due to the need for lighter cars to save fuel costs [43-45]. The high strength of a car body can be maintained using a newly developed thin steel sheet. However, the mechanical properties of materials are usually tested using a standard large sample, thus do not necessarily represent thin or small components' properties. This is the driving factor behind many studies surrounding the mechanical properties of micro-sized specimens used in the production of tiny metalbased components. In this study, the effect of tensile strain on the mechanical properties (i.e., hardness, tensile behaviour and fatigue strength) of a very thin 304 stainless steel sheet was investigated. The results were then compared to the fatigue strength of hardened 304 stainless steel.

\section{METHODS AND MATERIALS}

\section{Experimental Procedures}

This study used a very thin 304 stainless steel sheet with a thickness of $300 \mu \mathrm{m}$. The chemical composition of the material (wt. \%) is listed in Table 1. As shown in Figure 1, experimental samples were machined from $300 \mu \mathrm{m}$ sheets into dumbbell-shapes using an Electrical Discharge Machining (EDM) wire cutter according to ASTM E8 [46]. The width and length of gauge area were $5 \mathrm{~mm}$ and $28 \mathrm{~mm}$, respectively. Vickers hardness was implemented using the Zwich Roell Indentec micro-hardness tester according to ASTM E384 [47]. The hardness test was conducted on the surface sample with a $100 \mathrm{~g}$ load indenter and a dwell time of 15 seconds. The test was carried out ten times for each sample at different location points for two different cases: first, for the as-received material and second, for heat-treated material. The final Vickers hardness result was expressed as an average of the two. All the samples were annealed at $700^{\circ} \mathrm{C}$ to relieve the stress caused by the cold and EDM cutting process. Several tests were conducted to estimate the hardness, tensile strength and strain process of $2 \%$ and $5 \%$ of the annealed samples. The fatigue strength was then compared to that obtained by Bomidi et al. [48] for hardened 304 stainless steel according to ASTM E468 [49]. 
Table 1. Chemical composition (wt.\%).

\begin{tabular}{lllllll}
\hline $\mathrm{C}$ & $\mathrm{Mn}$ & $\mathrm{F}$ & $\mathrm{S}$ & $\mathrm{Si}$ & $\mathrm{Cr}$ & $\mathrm{Ni}$ \\
\hline 0.08 & 2.00 & 0.045 & 0.03 & 1.0 & $18.0-20.0$ & $8.0-11.0$ \\
\hline
\end{tabular}

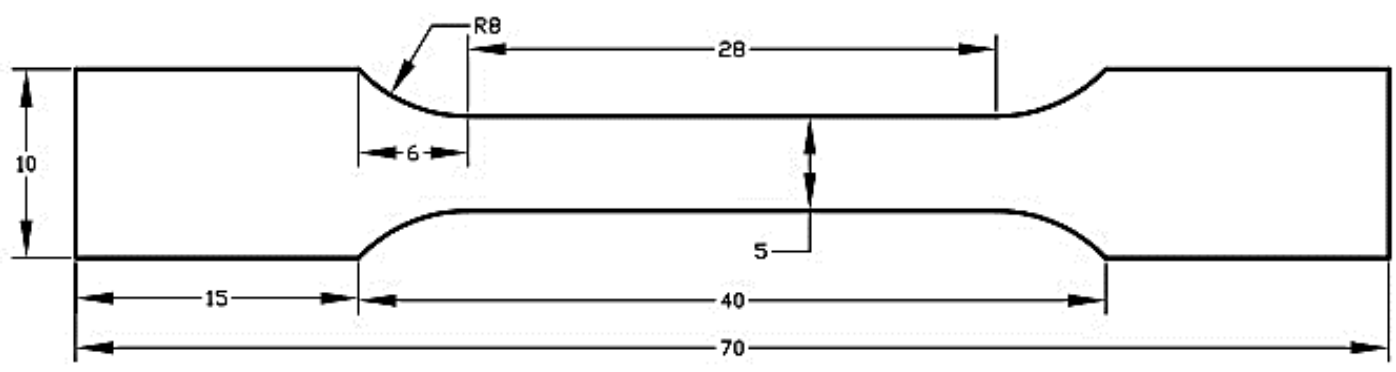

Figure 1. Tensile specimen size and configuration (units in $\mathrm{mm}$ ), thickness is $300 \mu \mathrm{m}$.

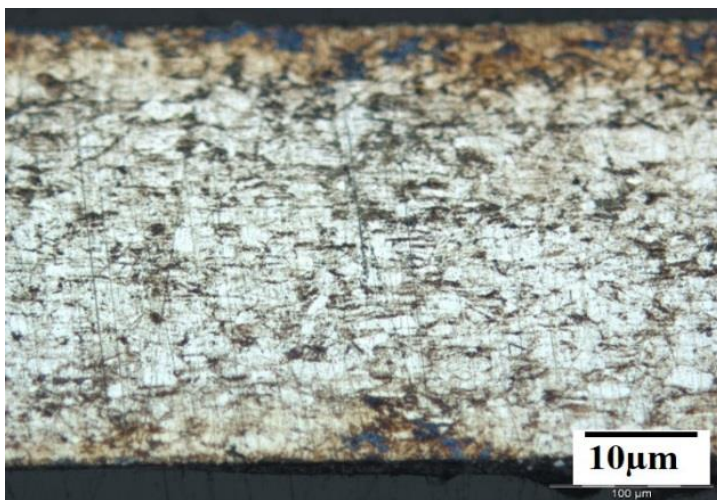

(a)

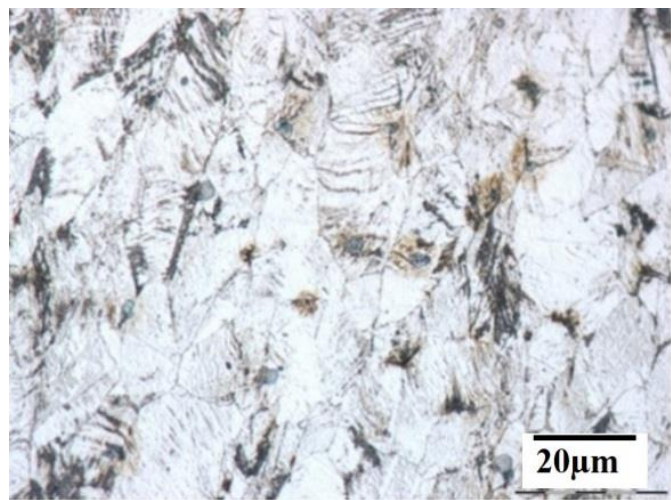

(b)

Figure 2. Microstructures of 304 stainless steel sheet with a thickness of $300 \mu \mathrm{m}$

(a) not annealed (b) after being annealed.

The tensile test was performed using a Zwick Roell Z100 universal testing machine of $100 \mathrm{kN}$ capacity. Three samples (as-received and heat-treated) were used. These samples were labelled 1, 2 and 3 and were ground using emery papers, polished using buff clothes with $1 \mu \mathrm{m}$ diamond suspension, before being etched to reveal the microstructure. The microstructures of $300 \mu \mathrm{m}$ thickness 304 stainless steel thin sheets without annealing are shown in Figure 2(a), and those after being annealed are shown in Figure 2(b). The grain size of the samples was about 20-25 $\mu \mathrm{m}$. All fractured surfaces of tensile and fatigue samples were then observed using Scanning Electron Microscopy (SEM). Broken specimens after the tensile and fatigue tests were fixed to a jig before put in a vacuum chamber for SEM observation. The SEM used was the EVO series by Zeiss. $15 \mathrm{kv}$ was used for the imaging of the fractured surface.

\section{RESULTS AND DISCUSSION}

\section{Vickers Hardness Test}

Hardness testing is very useful for the quality control of manufacturing processes, evaluation of materials, and for research and development purposes. Although hardness 
is empirical in nature, it is also an indication of ductility. Hardness may also correlate to tensile strength in many metals. In this study, the Vickers hardness test was conducted on the sample surface with a load indenture of $100 \mathrm{~g}$ and a dwell time of 15 seconds, according to ASTM E384 [47]. The test was carried out on two different cases: first, for the as-received material, which exhibited an average Vickers hardness of 387; and second, for the heat-treated material, which exhibited an average Vickers hardness of 357 (Figure 3). The reduced hardness in the heat-treated samples could have been contributed by the stress released and softening caused by the heat treatment process. This is because the recrystallization of the ferrite structure causes a reduction of carbon (due to diffusion), increases ductility and reduces hardness as reported by Mudashiru and Adio [50]. However, the samples' hardness decreased with increasing tempering temperature as mentioned by some researchers such as Fadare et al., Shrestha et al., and Ismail et al. [5153].

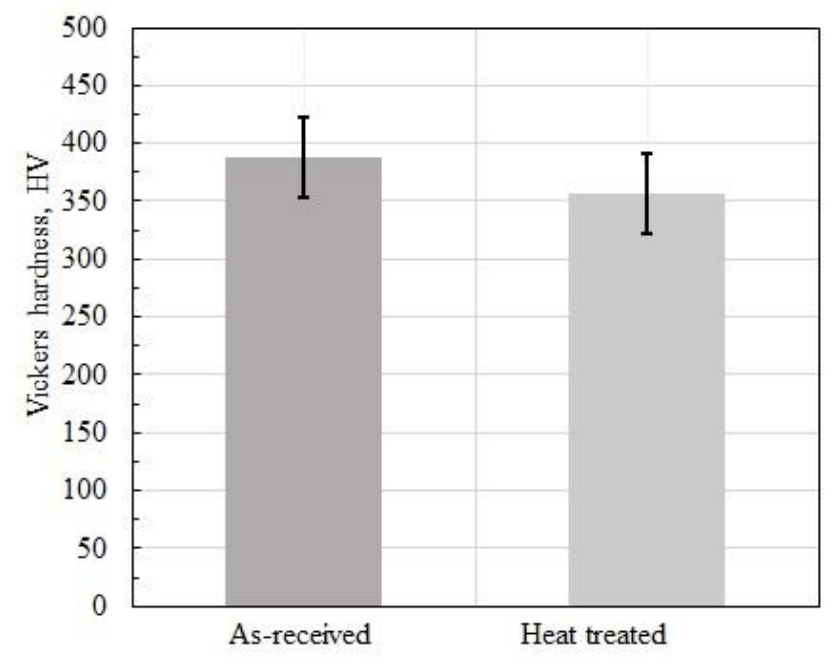

Figure 3. Micro Vickers hardness of $300 \mu \mathrm{m}$ thickness 304 stainless steel thin sheet for as-received and heat-treated specimens.

\section{Tensile Properties}

The stress-strain curves for the $300 \mu \mathrm{m}$ thickness 304 stainless steel sheets are shown in Figure 4. A summary of the tensile properties is listed in Table 2. Three samples were tested from the as-received and heat-treated specimens. These samples were labelled 1, 2 and 3 for each condition. The physical behaviour of the specimens was observed from its initial loading until specimen failure same as reported by Al-Bakri et al. [54]. Initially, both samples under the different conditions were loaded in the elastic range until they reached their respective elastic limits. Thereafter, both samples behaved differently. The heat-treated specimens exhibited a smoother stress-strain curve from the proportional limit to the ultimate stress level compared to the as-received specimens (Figure 4). For the non-heated specimens, the yield stress was evaluated based on the load at $0.2 \%$ strain. The ultimate tensile strength was found at $1240 \mathrm{MPa}$. Beyond the maximum point, the stress gradually decreased and the specimens failed at about $42 \%$ strain. However, this yield point $(786 \mathrm{MPa})$ was much lower than the $0.2 \%$ yield stress of the non-heated specimens (893MPa). The upper yield point in heat-treated specimens was followed by a sudden reduction in stress to the lower yield point. At this stage, the specimens continued 
to elongate without a significant change in their stress level for up to about $5 \%$ strain. The load increment was resulted in increasing strain values.

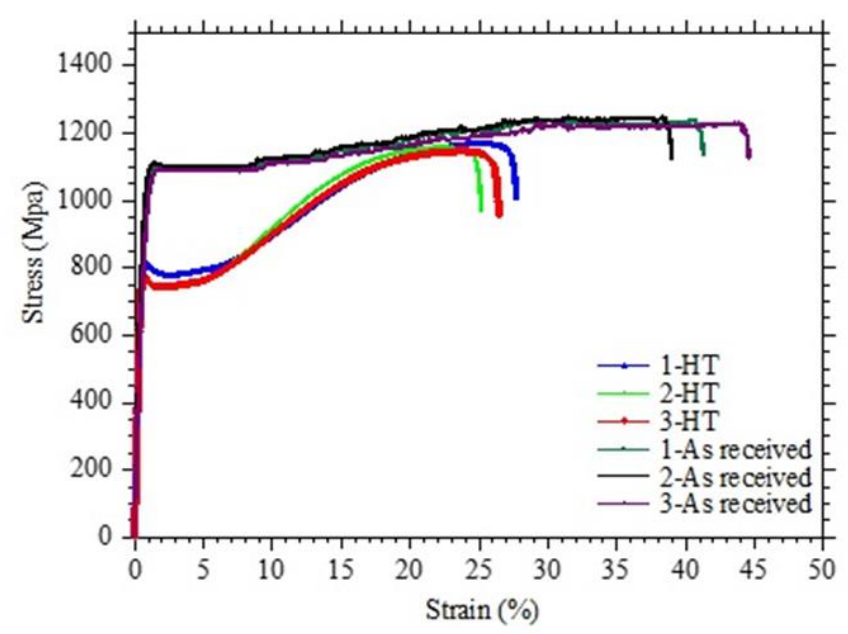

Figure 4. Stress-strain curves of $300 \mu \mathrm{m}$ thickness 304 stainless steel sheets for asreceived and heat-treated specimens.

Table 2. Tensile properties of $300 \mu \mathrm{m}$ thickness 304 stainless steel sheets for as-received and heat-treated specimens.

\begin{tabular}{lllll}
\hline & E $(\mathrm{GPa})$ & бy $(\mathrm{MPa})$ & б $_{\text {UTS }}(\mathrm{MPa})$ & El. $(\%)$ \\
\hline As received & 171 & 893 & 1240 & 42 \\
HT & 209 & 786 & 1160 & 26 \\
\hline
\end{tabular}

After the annealing treatment, the room temperature yield stress of the $300 \mu \mathrm{m}$ heat-treated specimens decreased from $893 \mathrm{MPa}$ to $786 \mathrm{MPa}$, the ultimate strength decreased from $1240 \mathrm{MPa}$ to $1160 \mathrm{MPa}$, and the tensile elongation decreased from $42 \%$ to $26 \% \mathrm{v}$ compared to the as-received specimens as mentioned by Wang et al. [55]. These results were similar to those reported by Wang et al. [55]. The Young's modulus values were $209 \mathrm{GPa}$ and $171 \mathrm{GPa}$ for the heat-treated and as-received specimens respectively (Table 2). After the heat treatment, the material softened and the stress due to manufacturing process, i.e. rolling process, was released. Therefore, the tensile yielding and hardness reduced are as shown in Figures 3 and 4. The heat treatment caused the increase in the work hardening rate, but also resulted in the reduction of tensile elongation.

\section{Fatigue Strength Test}

The S-N curves compare the fatigue strengths of 304 stainless steel sheets under heat treatment and strained to $0 \%, 2 \%$ and 5\% samples with those after hardening by [48] as shown in Figure 5. The samples subjected to 5\% strain had a higher fatigue life than the samples subjected to 2\% strain, 0\% strain and the hardened 304 stainless steel. Samples with $5 \%$ strain showed the highest endurance limit $(675 \mathrm{MPa})$ at $10^{7}$ cycles, followed by $2 \%$ strain samples $(650 \mathrm{MPa})$ and $0 \%$ strain samples $(600 \mathrm{MPa})$. The endurance limit for hardened samples was the lowest at $585 \mathrm{MPa}$. This difference proves that higher strain values lengthen the fatigue life cycles and endurance limit of 304 stainless steel due to 
both work-hardening and strain-induced martensitic transformation. This further proves that the process of inducing the 5\% strain was successful in improving fatigue strength. This is because the straining process induced a large amount of dislocations, resulting in increased tensile strength and better balance between hardness and ductility as mentioned by Nakajima et al. and Uematsu et al. [56,57].The straining process had a positive impact on the sample by delaying the generation and propagation of fatigue cracks. The crack propagation could have also been delayed by the hardened element as reported by Nakajima et al. and Nakajima et al. [58, 59]. Furthermore, the straining process provided high fatigue resistance to the material before the material finally failed.

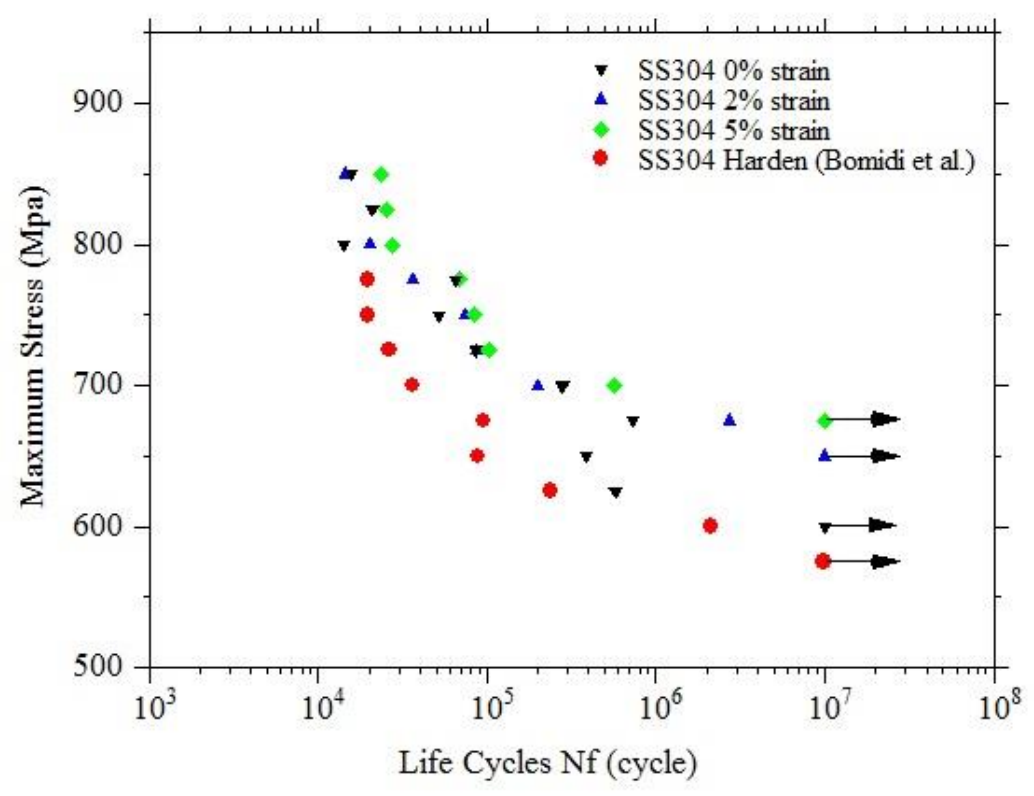

Figure 5.Comparison of S-N curves of SS304 heat treated and strained 0\%, 2\% and 5\% samples, and hardened SS304 [48].

\section{Fracture Behaviour Analysis}

\section{Fracture Behaviour for Tensile Test}

The fractured surface was observed using a Scanning Electron Microscope (SEM) for the as-received and heat-treated 304 stainless steel sheet samples of $300 \mu \mathrm{m}$ thickness. The observations were made after the tensile tests were conducted to analyse the failure processes as shown in Figures 7 and 8. Figure 7 clearly shows small tensile dimples, cleavage and voids on the fractured surfaces of the specimens. The void seems to be less significant in becoming a fatigue crack initiation site compared to the damage induced by the localized dislocation and slip of persistent slip bands. Figure 8 shows a general phenomenon of significant necking. A reduction in thickness direction can be seen in Figure 8(a). Magnified observation shows small tearing with some dimples on the fractured surface of the sample as seen in Figure 8(b). However, the fractured surfaces of the heat-treated samples appear to be rougher with an apparent tear pattern associated with the dimples. This is because martensite fraction has a major influence on void nucleation and growth as reported by Chen et al. [60]. Figure 6 shows the fractured shape of the samples. 


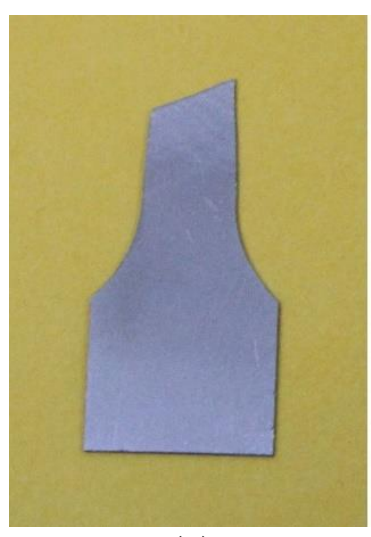

(a)

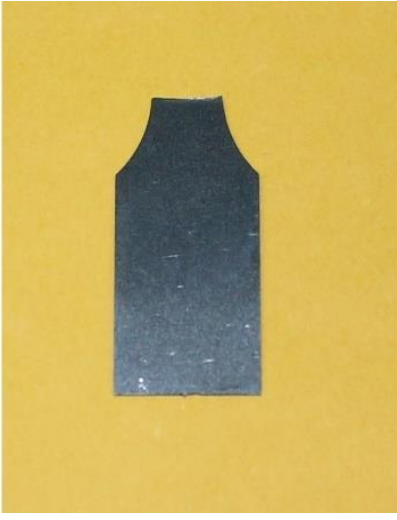

(b)

Figure 6. Fracture shape of samples (a) tensile (b) fatigue.

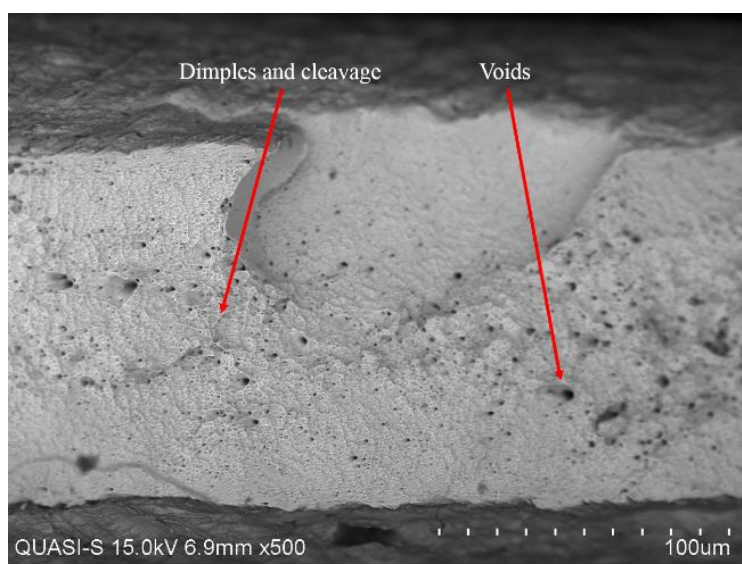

Figure 7. SEM fracture surface of as-received tensile specimens of 304 stainless steel sheet with $300 \mu \mathrm{m}$ thickness (500X magnification).

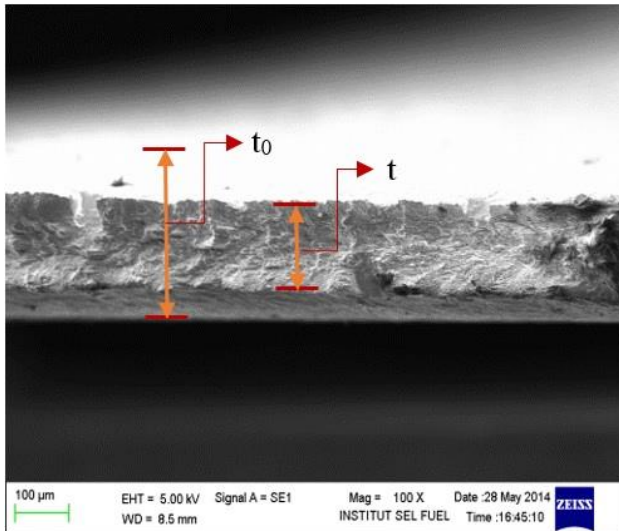

(a)

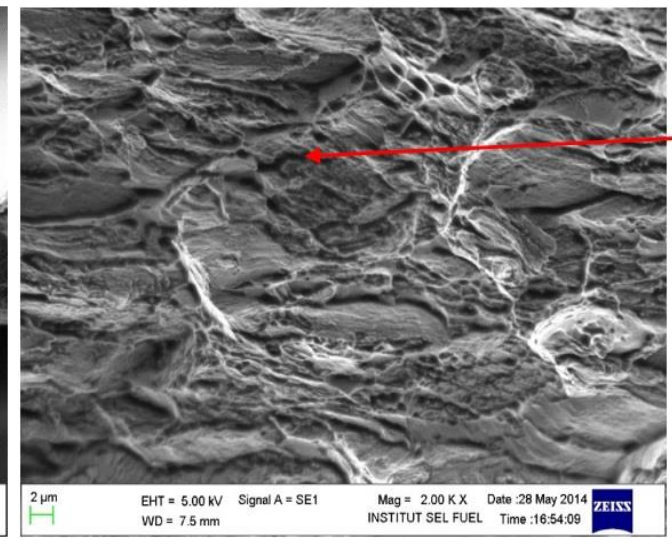

(b)
Tearing with some dimples

Figure 8. SEM fracture surface of heat treated tensile specimens of 304 stainless steel sheet with $300 \mu \mathrm{m}$ thickness with (a) $100 \mathrm{X}$ magnification, $\mathrm{t} 0=$ specimen thickness before tensile test and $\mathrm{t}=$ specimen thickness after tensile test and (b) $2000 \mathrm{X}$ magnification.

\section{Fracture Behaviour for Fatigue Test}

There were some differences in the fracture behaviour of the samples with $2 \%$ strain and that with the $5 \%$ strain. These differences can be seen in Figure 9. It shows the strain on 
the 304 stainless steel sample when subjected to fatigue crack propagation area; the area is seen to shrink rapidly with growing cracks. The resulting surface is curved and undulated. This is because the strain had caused an increase in the density of dislocations and slips on the plane of the material microstructure as reported by Chen et al. and Shintani and Murata $[60,61]$. The increase in both of these cases resulted in micro-cracks which further led to the generation of cracks. As the crack propagation process began, micro-cracks started connecting and caused faster crack propagation, thereby lowering the fatigue life of the material. In addition, samples that were subjected to $2 \%$ and $5 \%$ strains also showed a difference in their fractured surfaces. Samples subjected to the 5\% strain had a smaller fatigue crack propagation area than the samples subjected to the $2 \%$ strain. This happened because in the case of the sample with the 5\% strain, the value of the stresses became greater than the stress applied to the $2 \%$ strain. This increased the density of dislocations and slip planes, thereby contributing to the occurrence of microcracks larger than those caused to the $2 \%$ strain as mentioned by Chen et al. and Shintani and Murata $[60,61]$. These micro-cracks had led to the process of crack generation and rapid crack propagation.

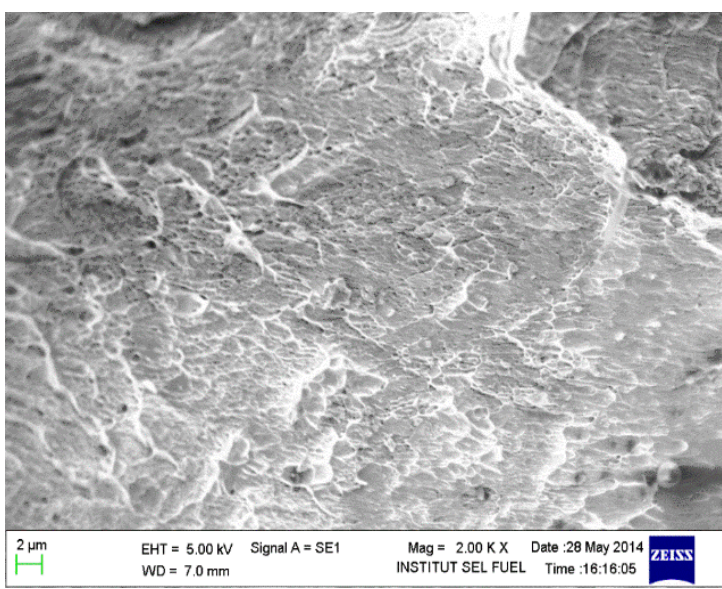

(a)

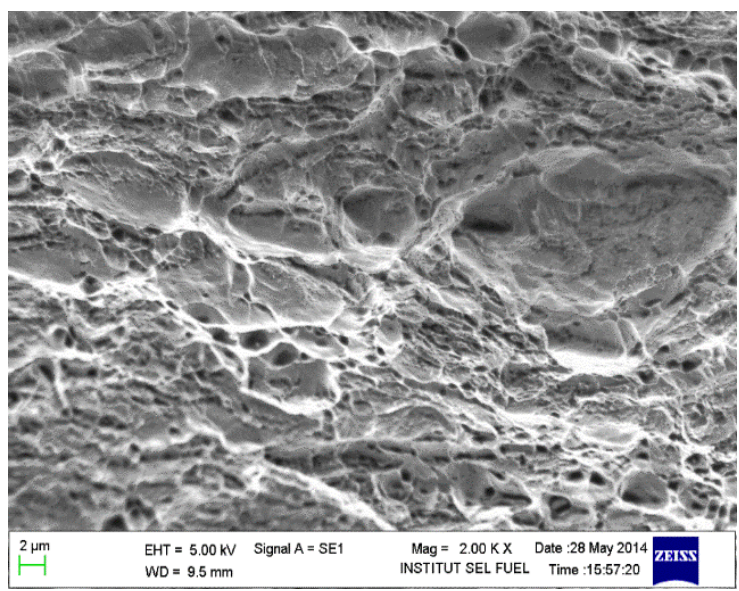

(b)

Figure 9. SEM of fractured surface of 304 stainless steel sheet fatigue test specimens at $300 \mu \mathrm{m}$ thickness with (a) $2 \%$ strain and (b) $5 \%$ strain.

\section{CONCLUSIONS}

The conclusions obtained from experimentation on the fatigue properties of strained 304 stainless steel materials can be summarized as follows;

Heat treatment on the mechanical properties of the 304 stainless steel had influenced the $300 \mu \mathrm{m}$ samples. All samples showed differences in their Young's modulus, yield stress, ultimate tensile strength, elongation and hardness values. However, the $300 \mu \mathrm{m}$ samples showed its highest ductility in both heat-treated and non-heat treated conditions. Furthermore, the as-received samples exhibited higher ultimate tensile strength compared to that shown by the heat-treated samples. Meanwhile, the heat-treated specimens exhibited a smooth stress-strain curve from the proportional limit to the ultimate stress level compared to the stress-strain curve of the as-received specimens.

The fatigue test showed that the specimen with a higher strain value of $5 \%$ lengthened the fatigue life cycle more than by the $2 \%$ strained, 304 stainless steel and by the $0 \%$ strained, hardened 304 stainless steel. However, the fracture behaviour for tensile test showed small tension dimples, cleavage and voids on the fractured surfaces of the as- 
received specimens. There was a clear reduction in the thickness direction of the heattreated specimens (lower magnification) for the tensile tested samples. The fractured surfaces of the heat-treated specimens turned out to be rougher (on higher magnification) owing to the presence of a tearing pattern associated with the dimples.

\section{ACKNOWLEDGEMENTS}

The authors would like to express their gratitude to the Malaysian Ministry of Education (MOE) and Universiti Kebangsaan Malaysia for a research grant (DIP-2014-024). A special mention of gratitude to the UKM-Zwick Roell Advanced Materials Research and Testing Laboratory, and Fuel Cell Institute, UKM for the facilities to carry out this work.

\section{REFERENCES}

[1] Marques SC, Rezende JdGOS, Alves LAdF, Silva BC, Alves E, Abreu LRd, et al. Formation of biofilms by Staphylococcus aureus on stainless steel and glass surfaces and its resistance to some selected chemical sanitizers. Brazilian Journal of Microbiology. 2007;38:538-43.

[2] Wright R. The high cycle fatigue strength of commercial stainless steel strip. Materials Science and Engineering. 1976;22:223-30.

[3] Lei L-P, Hwang S-M, Kang B-S. Finite element analysis and design in stainless steel sheet forming and its experimental comparison. Journal of Materials Processing Technology. 2001;110:70-7.

[4] Ha TK, Jeong HT, Sung HJ. High temperature bending fatigue behavior of stainless steels for automotive exhaust. Journal of Materials Processing Technology. 2007; 187-188:555-8.

[5] Shah LH, Akhtar Z, Ishak M. Investigation of aluminum-stainless steel dissimilar weld quality using different filler metals. International Journal of Automotive and Mechanical Engineering. 2013;8:1121-31.

[6] Jamil W, Aripin M, Sajuri Z, Abdullah S, Omar M, Abdullah M, et al. Mechanical properties and microstructures of steel panels for laminated composites in armoured vehicles. International Journal of Automotive and Mechanical Engineering. 2016;13(3): 3742-53.

[7] Lee S, Kim H, Yun D-J, Rhee S-W, Yong K. Resistive switching characteristics of $\mathrm{ZnO}$ thin film grown on stainless steel for flexible nonvolatile memory devices. Applied Physics Letters. 2009;95:262113.

[8] Hadrboletz A, Weiss B, Khatibi G. Fatigue and fracture properties of thin metallic foils. International Journal of Fracture. 2001;107:307-27.

[9] Connolley T, Mchugh P, Bruzzi M. A review of deformation and fatigue of metals at small size scales. Fatigue \& Fracture of Engineering Materials and Structures. 2005;28:1119-52.

[10] Bell T. Steel Applications from https://www.thebalance.com.

[11] Nilsson J-O. History and applications of stainless steel -from www.stainless-steelworld.net. Stainless Steel World magazine.

[12] Molak RM, Paradowski K, Brynk T, Ciupinski L, Pakiela Z, Kurzydlowski KJ. Measurement of mechanical properties in a 316L stainless steel welded joint. International Journal of Pressure Vessels and Piping. 2009;86:43-7.

[13] Engel U, Eckstein R. Microforming-from basic research to its realization. Journal of Materials Processing Technology. 2002;125-126:35-44. 
[14] Su HS, Chen FK, Tu KY, Menary G. Micro-Drawing of Circular Cups with Thin Stainless Steel Sheets. AIP Conference Proceedings: AIP; 2011. p. 270-5.

[15] Liu H, Sha C, Shen Z, Li L, Gao S, Li C, et al. Fabrication of dish-shaped micro parts by laser indirect shocking compound process. Micromachines. 2016;7:105.

[16] Neugebauer C. Tensile properties of thin, evaporated gold films. Journal of Applied Physics. 1960;31:1096-101.

[17] Doerner M, Gardner D, Nix W. Plastic properties of thin films on substrates as measured by submicron indentation hardness and substrate curvature techniques. Journal of Materials Research. 1986;1:845-51.

[18] Chan W, Fu M, Lu J, Liu J. Modeling of grain size effect on micro deformation behavior in micro-forming of pure copper. Materials Science and Engineering: A. 2010;527:6638-48.

[19] Jaswin MA, Lal DM. Effect of cryogenic treatment on the tensile behaviour of En 52 and $21-4 \mathrm{~N}$ valve steels at room and elevated temperatures. Materials \& Design. 2011;32:2429-37.

[20] Zakaria KA, Suhadak FHA, Ali MB, Abdullah S, Ghazali MJ. Influence of mechanical properties on load sequence effect and fatigue life of aluminium alloy. Journal of Mechanical Engineering and Sciences. 2017;14:2469-77.

[21] Shaari MS, Ariffin AK, Takahashi A, Abdullah S, Kikuchi M, Akramin MRM. Fatigue crack growth analysis on square prismatic with embedded cracks under tension loading. Journal of Mechanical Engineering and Sciences. 2017;14:251125.

[22] Zakaria KA, Jimit RH, Ramli SNR, Aziz AA, Bapokutty O, Ali MB. Study on fatigue life and fracture behaviour of fibreglass reinforced composites. Journal of Mechanical Engineering and Sciences. 2016;10:2300-10.

[23] Shaari MS, Akramin MRM, Ariffin AK, Abdullah S, Kikuchi M. Prediction of fatigue crack growth for semi-elliptical surface cracks using S-version fem under tension loading. Journal of Mechanical Engineering and Sciences. 2016;10:237586.

[24] Hussain F, Abdullah S, Nuawi MZ. Effect of temperature on fatigue life behaviour of aluminium alloy AA6061 using analytical approach. Journal of Mechanical Engineering and Sciences. 2016;10:2324-35.

[25] Mohamed MA, Manurung YHP, Ghazali FA, Karim AA. Finite element-based fatigue life prediction of a load-carrying cruciform joint. Journal of Mechanical Engineering and Sciences. 2015;8:1414-25.

[26] Taheri S, Taleb L. Effect of over-hardenning on high cycle thermal fatigue of austenitic stainless steels. Plasticity 20072007.

[27] Hauet A, Taleb L, Taheri S. Mécanismes explicatifs de l'influence du préécrouissage sur la fatigue de deux nuances d'aciers 304. Congrès Algérien de Mécanique2009.

[28] Taleb L, Hauet A. Multiscale experimental investigations about the cyclic behavior of the 304L SS. International Journal of Plasticity. 2009;25:1359-85.

[29] Hauet A, Taleb L, Taheri S. Correlations between microstructures at failure and LCF life time of 304L pre-strained steel. 16th International symposium on plasticity and its current applications St Kitts; 2010. p. 3-8.

[30] Kundu A, Chakraborti PC. Effect of strain rate on quasistatic tensile flow behaviour of solution annealed 304 austenitic stainless steel at room temperature. Journal of Materials Science. 2010;45:5482-9. 
[31] Kamal M, Rahman MM. Fatigue life prediction of titanium alloy for block loading using the hybrid approach of critical plane and continuum damage mechanics. International Journal of Automotive and Mechanical Engineering. 2017;14:408096.

[32] Sivananth V, Vijayarangan S. Fatigue Life Analysis and Optimization of a Passenger Car Steering Knuckle under Operating Conditions. International Journal of Automotive and Mechanical Engineering. 2015;11:2417-29.

[33] Kamal M, Rahman MM. An Integrated Approach for Fatigue Life Estimation Based on Continuum Mechanics Theory and Genetic Algorithm. International Journal of Automotive and Mechanical Engineering. 2015;11:2756-70.

[34] Hecker S, Stout M, Staudhammer K, Smith J. Effects of strain state and strain rate on deformation-induced transformation in 304 stainless steel: Part I. Magnetic measurements and mechanical behavior. Metallurgical Transactions A. 1982;13:619-26.

[35] Byun T, Hashimoto N, Farrell K. Temperature dependence of strain hardening and plastic instability behaviors in austenitic stainless steels. Acta Materialia. 2004;52:3889-99.

[36] Etienne A, Radiguet B, Genevois C, Le Breton J-M, Valiev R, Pareige P. Thermal stability of ultrafine-grained austenitic stainless steels. Materials Science and Engineering: A. 2010;527:5805-10.

[37] Das A, Sivaprasad S, Ghosh M, Chakraborti P, Tarafder S. Morphologies and characteristics of deformation induced martensite during tensile deformation of 304 LN stainless steel. Materials Science and Engineering: A. 2008;486:283-6.

[38] Das A, Tarafder S. Experimental investigation on martensitic transformation and fracture morphologies of austenitic stainless steel. International Journal of Plasticity. 2009;25:2222-47.

[39] Hedström P, Lindgren L-E, Almer J, Lienert U, Bernier J, Terner M, et al. Load partitioning and strain-induced martensite formation during tensile loading of a metastable austenitic stainless steel. Metallurgical and Materials Transactions A. 2009;40:1039-48.

[40] Haušild P, Davydov V, Drahokoupil J, Landa M, Pilvin P. Characterization of strain-induced martensitic transformation in a metastable austenitic stainless steel. Materials \& Design. 2010;31:1821-7.

[41] Zhang L, An B, Iijima T, Fukuyama S, Yokogawa K. Anomalous plastic deformation and martensitic transformation in metastable austenitic steels at low strain rate characterized by in-situ hydrogen and argon releases and scanning probe microscopy. Journal of Applied Physics. 2011;110:033540.

[42] Shen Y, Li X, Sun X, Wang Y, Zuo L. Twinning and martensite in a 304 austenitic stainless steel. Materials Science and Engineering: A. 2012;552:514-22.

[43] Kamal M, Rahman MM. Fatigue Life Estimation Based on Continuum Mechanics Theory with Application of Genetic Algorithm. International Journal of Automotive and Mechanical Engineering. 2015;11:2686-98.

[44] Kamal M, Rahman MM. Dual-Criteria Method for Determining Critical Plane Orientation for Multiaxial Fatigue Prediction Using a Genetic Algorithm. International Journal of Automotive and Mechanical Engineering. 2015;11:257181.

[45] Asif Iqbal AKM, Arai Y. Study on Low-Cycle Fatigue Behavior of Cast Hybrid Metal Matrix Composites. International Journal of Automotive and Mechanical Engineering. 2015;11:2504-14. 
[46] ASTM E8-04. Standard Test Methods for Tension Testing of Metallic Materials. Annual Book of ASTM Standards ASTM; 2004.

[47] E384 A. Standard Test Method for Knoop and Vickers Hardness of Materials. ASTM Stand. 2012:1-43.

[48] Bomidi JA, Weinzapfel N, Wang C-P, Sadeghi F. Experimental and numerical investigation of fatigue of thin tensile specimen. International Journal of Fatigue. 2012;44:116-30.

[49] E468 A. Standard Practice for Presentation of Constant Amplitude Fatigue Test Results for Metallic Materials. West Conshohocken: PA; 2011.

[50] Mudashiru L, Adio T. Study of effects of Heat Treatment on the Hardness and Microstructure of Welded Low Carbon Steel Pipes. 2nd International Conference on Engineering and Technology Research2013.

[51] Fadare DA, Fadara TG, Akanbi O. Effect of heat treatment on mechanical properties and microstructure of NST 37-2 steel. Journal of Minerals and Materials Characterization and Engineering. 2011;10:299.

[52] Shrestha T, Alsagabi SF, Charit I, Potirniche GP, Glazoff MV. Effect of heat treatment on microstructure and hardness of Grade 91 steel. Metals. 2015;5:13149.

[53] Ismail NM, Khatif NAA, Kecik MAKA, Shaharudin MAH. The effect of heat treatment on the hardness and impact properties of medium carbon steel. IOP Conference Series: Materials Science and Engineering; 2016. p. 012108.

[54] Al-Bakri AA, Sajuri Z, Ariffin AK, Razzaq MA, Fafmin MS. Tensile and fracture behaviour of very thin 304 stainless steel sheet. Jurnal Teknologi. 2016;78:45-50.

[55] Wang B, Huang L, Geng L, Rong X, Liu B. Effects of heat treatments on microstructure and tensile properties of as-extruded TiBw/near- $\alpha$ Ti composites. Materials \& Design. 2015;85:679-86.

[56] Nakajima M, Akita M, Uematsu Y, Tokaji K. Effect of strain-induced martensitic transformation on fatigue behavior of type 304 stainless steel. Procedia Engineering. 2010;2:323-30.

[57] Uematsu Y, Kakiuchi T, Akita M, Nakajima M, Nakamura Y, Yajima T. Effect of strain-induced martensitic transformation on high cycle fatigue behavior in cyclically-prestrained type 304. Zairyo. 2013;62:744-9.

[58] Nakajima M, Akita M, Uematsu Y, Tokaji K. Effects of Prestrain on Fatigue Behaviour in Type 316 Stainless Steel. Transactions of the Japan Society of Mechanical Engineers Series A. 2007;73:796-802.

[59] Nakajima M, Uematsu Y, Kakiuchi T, Akita M, Tokaji K, Murasaki T. Effects of Strain-Induced Martensitic Transformation on Fatigue Behavior of Type 304 Stainless Steel and Phase Transformation Analysis by EBSD. Journal of the Society of Materials Science, Japan. 2011;60:796-802.

[60] Li X, Chen J, Ye L, Ding W, Song P. Influence of strain rate on tensile characteristics of SUS304 metastable austenitic stainless steel. Acta Metallurgica Sinica (English Letters). 2013;26:657-62.

[61] Shintani T, Murata Y. Evaluation of the dislocation density and dislocation character in cold rolled Type 304 steel determined by profile analysis of X-ray diffraction. Acta Materialia. 2011;59:4314-22. 